\title{
Estimation of anticorrosive properties of thin tapes of binary and ternary copper alloys
}

\author{
Yu. V. Khlebnikova ${ }^{1, \uparrow}$, T. R. Suaridze ${ }^{1}$, D. P. Rodionov ${ }^{1}$, L. Yu. Egorova ${ }^{1}$, R. I. Gulyaeva ${ }^{2}$ \\ †yulia_kh@imp.uran.ru
}

${ }^{1}$ Mikheev Institute of Metal Physics Ural Branch RAS, 18 S. Kovalevskoi St., 620137, Yekaterinburg, Russia

${ }^{2}$ Institute of Metallurgy Ural Branch RAS, 101 Amundsena St., 620160, Yekaterinburg, Russia

Oxidation tendency of a series of binary copper-based and ternary copper-nickel-based alloys with additions of 3d-transition metals such as $\mathrm{Cr}, \mathrm{V}$ and Fe has been studied. Oxidation resistance is estimated by the use of thermogravimetry method at the temperature of $700^{\circ} \mathrm{C}$, which corresponds to the typical temperature of deposition of buffer and superconducting layers on metal substrates. It has been found that the tapes of binary alloys $\mathrm{Cu}-0.4 \% \mathrm{Cr}, \mathrm{Cu}-1.6 \% \mathrm{Fe}$ and $\mathrm{Cu}-0.6 \% \mathrm{~V}$ containing dispersed particles of a second phase with a crystal lattice different from that of the matrix have an oxidation resistance reduced inversely proportional to the particle size. A tape of $\mathrm{Cu}-0.6 \% \mathrm{~V}$ alloy, in which vanadium particles have sizes as large as few microns has been found to possess an even less oxidation resistance than the copper tape, so it cannot be used for epitaxial deposition of functional layers at high temperatures. Textured tapes of binary alloys $\mathrm{Cu}-0.4 \% \mathrm{Cr}$ and $\mathrm{Cu}-1.6 \% \mathrm{Fe}$ have better anticorrosion properties at the temperature of $700^{\circ} \mathrm{C}$ than tapes of pure copper but worse than those of ternary copper-nickel-based alloy tapes. It has been shown that textured tapes of ternary copper-nickel-based alloys containing 30 to $40 \% \mathrm{Ni}$ and $1-2$ wt. \% $\mathrm{Fe}, \mathrm{Cr}$ or V have a FCC solid solution structure without inclusions. $\mathrm{Cu}-40 \% \mathrm{Ni}-1.2 \% \mathrm{Cr}$ and $\mathrm{Cu}-40 \% \mathrm{Ni}-1.4 \% \mathrm{Fe}$ alloy tapes, in addition to perfect cubic texture and high strength properties, have significantly better anticorrosion properties at temperature $700^{\circ} \mathrm{C}$ than the tapes of pure copper and other alloys studied. Thus, they can be recommended for a use as substrates for epitaxial deposition of buffer and superconducting layers at high temperatures.

Keywords: copper-based alloys, cubic texture, thin tapes, thermogravimetry, surface structure, oxidation.

\section{Оценка антикоррозионных свойств тонких лент из двойных и тройных медных сплавов}

\author{
Хлебникова Ю. В. ${ }^{1 \dagger}$, Суаридзе Т. Р. ${ }^{1}$, Родионов Д. П. ${ }^{1}$, Егорова Л. Ю. ${ }^{1}$, Гуляева Р. И. ${ }^{2}$ \\ ${ }^{1}$ ФГБУН Институт физики металлов имени М.Н. Михеева УрО РАН, ул. С.Ковалевской 18, 620137, Екатеринбург, Россия \\ ${ }^{2}$ Институт металлургии УрО РАН, ул. Амундсена 101, 620160, Екатеринбург, Россия
}

В настоящей работе исследована склонность к окислению ряда двойных сплавов на основе меди и тройных сплавов на медно-никелевой основе с добавками 3d-переходных металлов, таких как $\mathrm{Cr}$, V и Fe. Cтойкость к окислению оценена с использованием метода термогравиметрии при температуре $700^{\circ} \mathrm{C}$, соответствующей характерной температуре нанесения буферных и сверхпроводящих слоев на металлическую подложку. Установлено, что в лентах из двойных сплавов $\mathrm{Cu}-0.4 \% \mathrm{Cr}, \mathrm{Cu}-1.6 \% \mathrm{Fe}$ и $\mathrm{Cu}-0.6 \% \mathrm{~V}$, содержащих дисперсные частицы второй фазы с отличным от матрицы типом кристаллической решетки, стойкость к окислению снижается обратно пропорционально размеру частиц. Лента из сплава $\mathrm{Cu}-0.6 \% \mathrm{~V}$, в которой частицы ванадия достигают размеров нескольких микрон, оказалась даже менее стойкой к окислению, чем медная лента, поэтому не может быть использована для эпитаксиального нанесения функциональных слоев при повышенных температурах. Текстурованные ленты из двойных сплавов $\mathrm{Cu}-0.4 \% \mathrm{Cr}$ и $\mathrm{Cu}-1.6 \% \mathrm{Fe}$ обладают лучшими антикоррозионными свойствами при температуре $700^{\circ} \mathrm{C}$, чем ленты из чистой меди, но уступают лентам из тройных сплавов на медно-никелевой основе. Показано, что текстурованные ленты из тройных сплавов на медно-никелевой основе с $30-40 \% \mathrm{Ni}$, содержащие 1-2 вес.\% Fe, Cr или V имеют структуру однородного ГЦК-твердого раствора без включений. Ленты из сплавов $\mathrm{Cu}-40 \% \mathrm{Ni}-1.2 \% \mathrm{Cr}$ и $\mathrm{Cu}-40 \% \mathrm{Ni}-1.4 \% \mathrm{Fe}$, помимо совершенной кубической текстуры и высоких прочностных свойств, обладают существенно лучшими антикоррозионными свойствами при температуре $700^{\circ} \mathrm{C}$, чем ленты из чистой меди и остальных исследованных сплавов, и могут быть рекомендованы для использования в качестве подложек для эпитаксиального нанесения буферных и сверхпроводящих слоев при повышенных температурах.

Ключевые слова: сплавы на основе меди, кубическая текстура, тонкие ленты, термогравиметрия, структура поверхности, окисление. 


\section{1. Введение}

Протяженные ленты-подложки с острой кубической текстурой из меди и медных сплавов, получаемые холодной прокаткой со степенями $\geq 97 \%$ и последующим рекристаллизационным отжигом, могут быть использованы для эпитаксиального нанесения многослойных функциональных композиций, в том числе в конструкции высокотемпературных сверхпроводящих проводов второго поколения (2G HTSC) [1-12]. Использование бинарных медных сплавов и тройных сплавов на медно-никелевой основе, легированных 3d-переходными элементами, такими как $\mathrm{Cr}, \mathrm{V}$ и Fе при создании металлических подложек с кубической текстурой для эпитаксиального нанесения высокотемпературных сверхпроводников направлено на повышение механических свойств тонкой ленты-подложки. В бинарных сплавах упрочнение достигается за счет выделения дисперсных частиц чистого легирующего элемента, в тройных за счет аддитивного вклада в твердорастворное упрочнение никеля и $3 \mathrm{~d}$-металла $[3-6,12]$. При этом сплав сохраняет немагнитность и остроту кубической текстуры, присущие медным лентам-подложкам. Упрочнение медного сплава, позволяет уменьшить толщину лентыподложки и, следовательно, вес всей конструкции $2 \mathrm{G}$ HTSC-провода.

Желательно, чтобы лента-подложка из медного сплава, кроме текстурованности, немагнитности и прочности, обладала более высокой стойкостью к окислению, чем лента из меди, особенно при температурах нанесения буферных и сверхпроводящих слоев. В зависимости от химического состава и толщины эпитаксиального слоя температура нанесения часто составляет $600-700^{\circ} \mathrm{C}[13,14]$. Например, в патенте [13] при создании архитектуры substrat/Pd/CeO $/ \mathrm{YSZ} / \mathrm{YBCO}$ эпитаксиальный буферный слой YSZ наносили в интервале температур от 500 до $820^{\circ} \mathrm{C}$, а слой палладия - при температурах от 200 до $700^{\circ} \mathrm{C}$. В другом патенте [14] на текстурованные подложки из меди проводили нанесение эпитаксиальных слоев $\mathrm{ZrO}_{2}$, YSZ или $\mathrm{HfO}_{2}$ при температуре от 500 до $800^{\circ} \mathrm{C}$.

Анализ антиокислительных свойств медных сплавов с малыми добавками 3d-переходных металлов, таких как $\mathrm{Cr}, \mathrm{V}$ и $\mathrm{Fe}$, позволяющих достичь высокий уровень упрочнения ленты-подложки представляет большой интерес. Эти сплавы значительно дешевле никелевых сплавов, используемых в настоящее время в технологии 2G HTSC. Делать какие-либо прогнозы, касающиеся антикоррозионных свойств текстурованных лент из этих сплавов, сложно. В литературе есть лишь сведения о коррозионной стойкости стареющих электротехнических хромовых бронз типа БрХ0.5 [15], причем речь идет конечно о результатах испытаний массивных образцов.

На основе анализа литературных данных можно заключить, что антикоррозионные свойства текстурованных лент из сплава $\mathrm{Cu}-40 \% \mathrm{Ni}$ в температурном интервале нанесения эпитаксиальных слоев должны быть более высокими, чем лент из чистой меди [15]. Поэтому есть основания полагать, что текстурованные ленты из тройных сплавов на основе $\mathrm{Cu}-40 \% \mathrm{Ni}$ с добавками тех же легирующих элементов будут более стойкими к окислению, чем бинарные сплавы.

В настоящей работе проводится сравнительный анализ антикоррозионных свойств текстурованных лент бинарных $\mathrm{Cu}-\mathrm{Me}$ и тройных $\mathrm{Cu}-40 \% \mathrm{Ni}-\mathrm{Me}(\mathrm{Me}=\mathrm{Cr}, \mathrm{V}, \mathrm{Fe})$ сплавов с лентами из чистой меди при температуре $700^{\circ} \mathrm{C}$. Склонность сплавов к окислению оценивается с использованием метода термогравиметрии.

\section{2. Материал и методика эксперимента}

Для исследования были выплавлены сплавы $\mathrm{Cu}-1.6 \% \mathrm{Fe}, \mathrm{Cu}-0.4 \% \mathrm{Cr}, \mathrm{Cu}-0.6 \% \mathrm{~V}, \mathrm{Cu}-40 \% \mathrm{Ni}-1.4 \% \mathrm{Fe}$, $\mathrm{Cu}-40 \% \mathrm{Ni}-1.2 \% \mathrm{Cr}$ и $\mathrm{Cu}-40 \% \mathrm{Ni}-1.1 \% \mathrm{~V}$ на основе чистой, бескислородной меди Сu0б чистотой 99.95\%. При выплавке использовали никель чистотой 99.99\%, хром чистотой не ниже 99.93\%, переплавленный ванадий и карбонильное переплавленное железо чистотой 99.94\%. Состав сплавов и чистота материалов указаны в весовых \%.

Все операции по выплавке сплавов, холодной деформации заготовок и рекристаллизационным отжигам деформированных лент для получения острой кубической текстуры подробно описаны в работах $[3,4,11,12]$. Максимальная степень текстурного совершенства с долей кубических зерен на поверхности ленты $\geq 95 \%$ достигается для двойных сплавов после рекристаллизационного отжига в интервале температур $700-750^{\circ} \mathrm{C}$, для тройных сплавов $-1000-1050^{\circ} \mathrm{C}[3,5,12]$.

Термогравиметрические исследования по склонности меди и медных сплавов к окислению проводили в ЦКП "Урал-М" Института металлургии УрО РАН. Использовали прибор Netzsch STA 449C Jupiter для совмещенных термогравиметрического и термического анализов. Опыты проводились в воздушной среде при нагреве до $700^{\circ} \mathrm{C}$ со скоростью 40 град/мин в потоке воздуха (40 мл/мин) с использованием предварительно прокаленных тиглей из $\mathrm{Al}_{2} \mathrm{O}_{3}$. При $700^{\circ} \mathrm{C}$ проведена изотермическая выдержка продолжительностью 250 мин. Увеличение массы исчисляли в \% от исходной массы на единицу площади образца $\left(1 \mathrm{~cm}^{2}\right)$.

Структуру текстурованной поверхности лент исследовали непосредственно после рекристаллизационного отжига (без травления) на сканирующем электронном микроскопе FEI Quanta-200 в отделе электронной микроскопии ЦКП “Испытательный центр нанотехнологий и перспективных материалов” Института физики металлов имени М.Н. Михеева УрО РАН. Для исследования структурных изменений поверхности лент на ранних стадиях окисления проводили серию отжигов сплавов при $700^{\circ} \mathrm{C}$ с изотермическими выдержками продолжительностью 5 и 30 мин.

Содержание легирующих элементов и кислорода на поверхности образцов до и после термогравиметрического исследования определяли с использованием спектрометра EDAX для элементного анализа на микроскопе FEI Quanta-200. 


\section{3. Структура поверхности лент после прокатки и рекристаллизационного отжига}

В чистой меди сформировалась однородная структуpa со средним размером зерна $d_{\text {ср }} \sim 32$ мкм (рис. 1a). В сплавах $\mathrm{Cu}-1.6 \% \mathrm{Fe}, \mathrm{Cu}-0.6 \% \mathrm{~V}$ и $\mathrm{Cu}-0.4 \% \mathrm{Cr}$ заметна вытянутость зерен в направлении прокатки (рис. 1b). Это связано с наличием в структуре дисперсных частиц легирующего элемента - чистого хрома, железа или ванадия с ОЦК кристаллической решеткой, поэтому прокатке подвергается фактически двухфазная структура, хотя и с очень малой объемной долей второй фазы. Частицы в сплаве $\mathrm{Cu}-0.4 \% \mathrm{Cr}$ имеют размер от 20 до 100 нм [5], в сплаве $\mathrm{Cu}-1.6 \% \mathrm{Fe}$ - несколько крупнее от 50 до 200 нм [4], а в сплаве $\mathrm{Cu}-0.6 \% \mathrm{~V}$ выделившиеся частицы крупнее на порядок, наиболее крупные достигают $\sim 3$ мкм [3]. Структура поверхности текстурованных лент из всех тройных сплавов подобна структуре медной ленты, но размер зерна существенно больше. Средний размер зерна в структуре тройных сплавов составляет около 50 мкм. Это связано в первую очередь с применением более высокой температуры текстурообразующего отжига для тройных сплавов, по сравнению с медью, в которой максимальная степень текстурного совершенства была достигнута при отжиге $600^{\circ} \mathrm{C}$. Можно отметить высокую степень однородности структуры и практически полное отсутствие двойников.

\section{4. Результаты термогравиметрического исследования}

Полученные термогравиметрические кривые для текстурованных лент из сплавов $\mathrm{Cu}-\mathrm{Me}$ и $\mathrm{Cu}-40 \% \mathrm{Ni}-\mathrm{Me}$ показаны на рис. 2. Для сравнения приведено также изменение массы на единицу площади образца для текстурованных лент из чистой меди (кривая 1).

Двойной сплав $\mathrm{Cu}-1.6 \% \mathrm{Fe}$ окисляется менее активно, чем чистая медь (кривая 2). Еще меньшей склонностью к окислению обладает сплав $\mathrm{Cu}-0.4 \% \mathrm{Cr}$ (кривая 3).
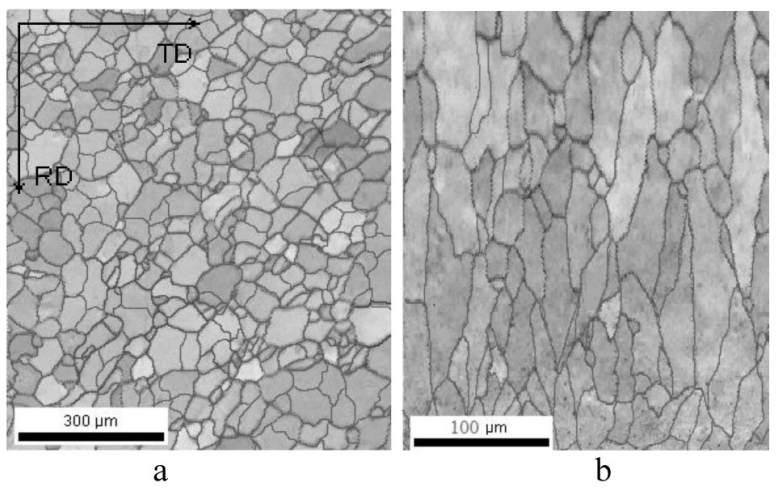

Рис. 1. Структура поверхности текстурованных лент из меди (a) и бинарного сплава $\mathrm{Cu}-1.6 \% \mathrm{Fe}$ (b). Сканирующая электронная микроскопия, изображение структуры получено в совмещенных вторичных и обратно рассеянных электронах.

Fig. 1. The Structure of the textured surface tapes of the copper (a) and a binary alloy $\mathrm{Cu}-1.6 \% \mathrm{Fe}$ (b). Scanning electron microscopy image of the structure obtained in the combined secondary and backscattered electrons.
Максимальную склонность к окислению демонстрирует сплав с ванадием, прибыль массы даже больше, чем для чистой меди (кривая 4).

Ленты из тройных сплавов на медно-никелевой основе окисляются менее активно, чем медь и бинарные сплавы. Сплав $\mathrm{Cu}-40 \% \mathrm{Ni}-1.1 \% \mathrm{~V}$ оказался заметно менее стойким к окислению, чем сплавы с железом и хромом, хотя и лучше, чем чистая медь и двойные сплавы (кривая 5). Сплавы $\mathrm{Cu}-40 \% \mathrm{Ni}-1.4 \% \mathrm{Fe}$ и $\mathrm{Cu}-40 \% \mathrm{Ni}-1.2 \% \mathrm{Cr}$ показали наименьшие значения прибыли массы (кривые 6 и 7).

\section{5. Структура окисленной поверхности лент}

Цель исследования структуры заключалась в выявлении преимущественных мест зарождения очагов коррозии. Методом рентгеноспектрального микроанализа определяли содержание легирующих элементов и кислорода на поверхности образцов до и после термогравиметрического исследования. На поверхности всех текстурованных лент до термогравиметрического исследования кислорода не обнаруживали.

После термогравиметрического исследования (выдержка 250 мин при $700^{\circ} \mathrm{C}$ ) на поверхности медной ленты сформировался плотный оксидный слой. Оксидная пленка хрупкая, имеет много трещин, края пленки в областях, прилегающих к трещинам, отслаиваются и откалываются. Содержание кислорода в оксидной пленке по данным микроанализа практически соответствует стехиометрическому составу закиси меди $\mathrm{Cu}_{2} \mathrm{O}$ (рис. 3a,b). На ранних стадиях окисления (выдержка при $700^{\circ} \mathrm{C}$ в течение 30 мин) сформировавшийся оксидный слой более тонкий и содержание кислорода несколько меньше соответствующего стехиометрическому составу закиси меди, в разных участках поверхности в среднем около 7 вес.\%. Анализ начальных стадий окисления (выдержка при $700^{\circ} \mathrm{C}$ в течение 5 мин) показывает, что процесс окисления происходит равномерно по всей поверхности текстурованной ленты.

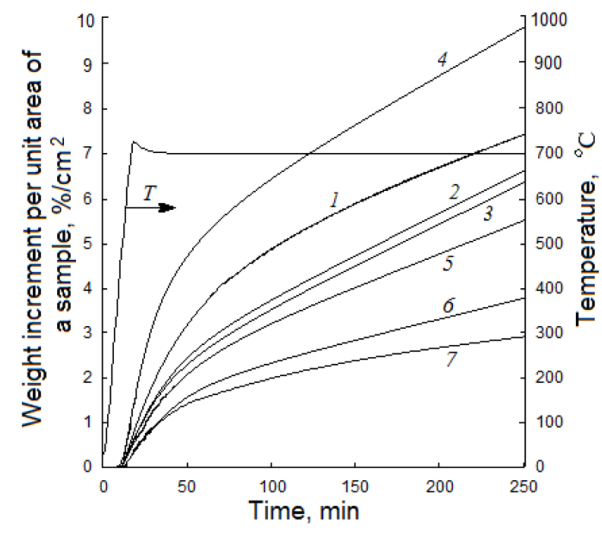

Рис. 2. Кинетические кривые окисления меди и медных сплавов: $1-\mathrm{Cu} ; 2-\mathrm{Cu}-1.6 \% \mathrm{Fe} ; 3-\mathrm{Cu}-0.4 \% \mathrm{Cr} ; 4-\mathrm{Cu}-0.6 \% \mathrm{~V} ; 5-\mathrm{Cu}-$ $40 \% \mathrm{Ni}-1.1 \% \mathrm{~V} ; 6-\mathrm{Cu}-40 \% \mathrm{Ni}-1.4 \% \mathrm{Fe} ; 7-\mathrm{Cu}-40 \% \mathrm{Ni}-1.2 \% \mathrm{Cr}$.

Fig. 2. Kinetic curves of the oxidation of cupper and copper alloys: $1-\mathrm{Cu} ; 2-\mathrm{Cu}-1.6 \% \mathrm{Fe} ; 3-\mathrm{Cu}-0.4 \% \mathrm{Cr} ; 4-\mathrm{Cu}-0.6 \% \mathrm{~V} ; 5-\mathrm{Cu}-$ $40 \% \mathrm{Ni}-1.1 \% \mathrm{~V} ; 6-\mathrm{Cu}-40 \% \mathrm{Ni}-1.4 \% \mathrm{Fe} ; 7-\mathrm{Cu}-40 \% \mathrm{Ni}-1.2 \% \mathrm{Cr}$. 
В текстурованной ленте из сплава $\mathrm{Cu}-1.6 \% \mathrm{Fe}$ значительная доля частиц имеет четкую кристаллографическую огранку. На ранних стадиях окисления (выдержка 30 мин при $700^{\circ} \mathrm{C}$ ) образование оксида на поверхности ленты из сплава $\mathrm{Cu}-1.6 \% \mathrm{Fe}$ идет не равномерно по всей поверхности, а более интенсивно на включениях железа. Частицы при этом теряют свою огранку (рис. 3c). Микроанализ регистрирует на частицах большее содержание кислорода, чем в матрице (рис. 3d,e). Такая же картина характерна и для сплава $\mathrm{Cu}-0.4 \% \mathrm{Cr}$. На более поздних стадиях окисления отдельные очаги растут и постепенно «сливаются» в сплошную поверхностную пленку. Более высокие антикоррозионные свойства ленты из сплава $\mathrm{Cu}-0.4 \% \mathrm{Cr}$, по сравнению с лентой из сплава $\mathrm{Cu}-1.6 \% \mathrm{Fe}$, связаны на наш взгляд с большей степенью дисперсности выделившихся частиц хрома. К тому же количество (плотность) частиц хрома в двойном медном сплаве несколько меньше, чем в сплаве с железом, поскольку количество легирующего элемента различается в 4 раза. В результате более мелкие оксидные очаги, образовавшиеся на частицах в сплаве $\mathrm{Cu}-0.4 \% \mathrm{Cr}$ разрастаются менее интенсивно.

На поверхности сплава $\mathrm{Cu}-0.6 \% \mathrm{~V}$, имеющего самые низкие антикоррозионные свойства, обнаруживаются многочисленные оксидные очаги даже после 5 мин выдержки при $700^{\circ} \mathrm{C}$. Первые окислы образуются, как и в двух предыдущих сплавах, на частицах. Поскольку размер выделившихся в сплаве $\mathrm{Cu}-0.6 \% \mathrm{~V}$ частицы более чем на порядок превышают размер частиц в сплавах с хромом и железом, то уже после выдержки при температуре $700^{\circ} \mathrm{C}$ в течение 30 мин доля поверхности, занятая многочисленными очагами коррозии приближается к $100 \%$. Такая активизация коррозии, связанная, на наш взгляд, с большим размером выделившихся в сплаве $\mathrm{Cu}-0.6 \% \mathrm{~V}$ частиц, приводит в конечном итоге к тому, что антикоррозионные свойства ленты из данного сплава не только хуже, чем в сплавах $\mathrm{Cu}-0.4 \% \mathrm{Cr}$ и $\mathrm{Cu}-1.6 \% \mathrm{Fe}$, но и заметно уступают лентам из чистой меди.

В тройных сплавах на медно-никелевой основе с теми же легирующими элементами $(\mathrm{Fe}, \mathrm{Cr}, \mathrm{V})$ концентрационные области однородного ГЦК-твердого раствора более широкие, чем с чистой медью. Поэтому структура тройных сплавов, содержащих 1-2 вес.\% $\mathrm{Cr}$, $\mathrm{Fe}$ или $\mathrm{V}$ однородная без включений [12]. При анализе электронно-дифракционных картин, снятых с текстурованных лент из всех тройных сплавов, не было обнаружено рефлексов от каких-либо фаз с другим типом кристаллической решетки, кроме ГЦК-матрицы.

После завершения термогравиметрических испытаний (выдержка 250 мин при $700^{\circ} \mathrm{C}$ ) на поверхности лент из всех исследованных тройных сплавов образовалась плотная окисная пленка, состав которой близок к стехиометрическому составу закиси меди $\mathrm{Cu}_{2} \mathrm{O}$. Оксидная пленка хрупкая, местами потрескалась и деформировалась. В качестве примера на рис. 4а приведен фрагмент структуры окисленной поверхности сплава $\mathrm{Cu}-40 \% \mathrm{Ni}-1.4 \% \mathrm{Fe}$. Вблизи трещин фрагменты верхних слоев окисной пленки откалываются и в этих участках фиксируется значительно более низкое содержание кислорода. В тех участках поверхности ленты, где не про-

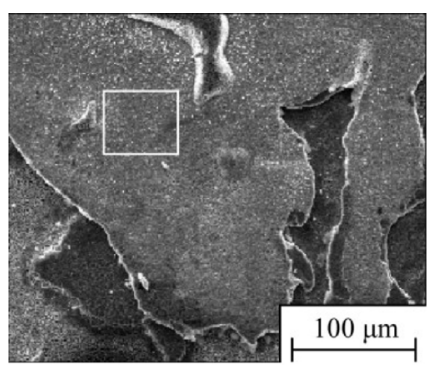

a

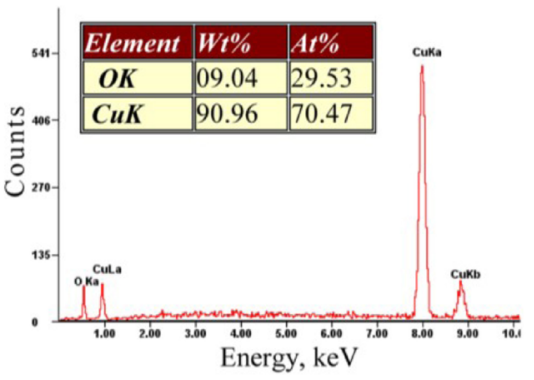

b

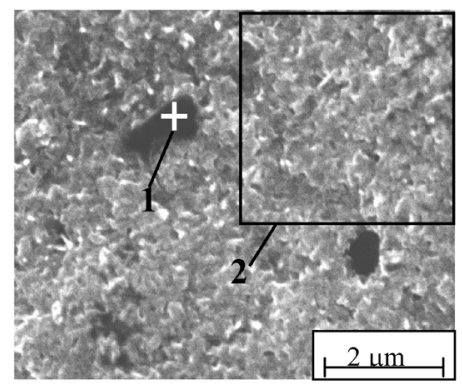

$\mathrm{c}$

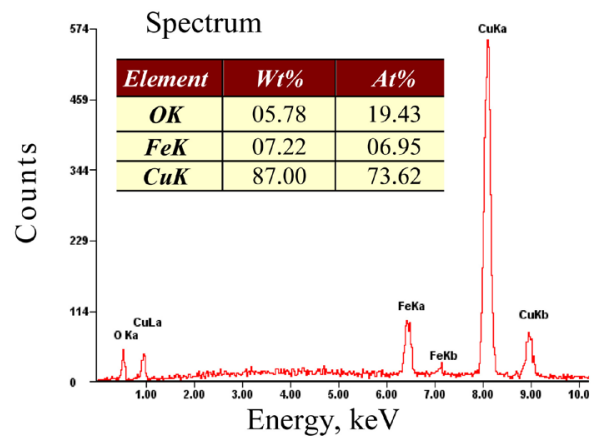

d

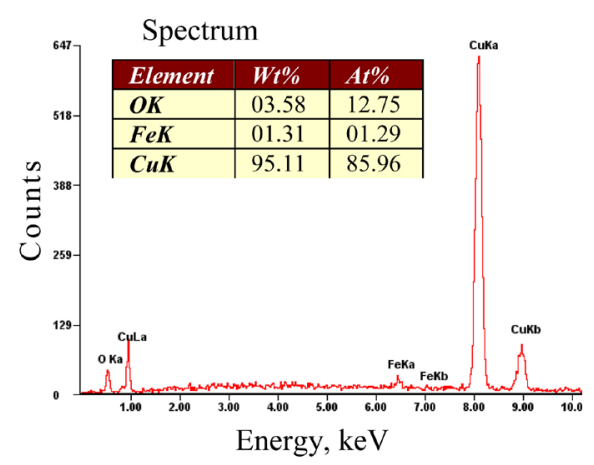

e

Pис. 3. Электронные микрофотографии поверхности лент из меди после завершения термогравиметрических испытаний (a) и сплава $\mathrm{Cu}-1.6 \% \mathrm{Fe}$ на ранних стадиях окисления (c) и спектры с поверхности медной ленты (b) и сплава (d, e).

Fig. 3. Electron micrographs of the surface of cupper tape (a) and of the alloy $\mathrm{Cu}-1.6 \% \mathrm{Fe}$ tape in the early stages of oxidation (c) and spectrum of cupper surface (b) and of the alloy (d, e). 
изошло растрескивания и скалывания пленки, содержание кислорода около 10 вес.\% (рис. 4b).

На поверхности лент из сплавов на медно-никелевой основе с $\mathrm{Cr}$ и Fe уже на самых ранних стадиях окисления (выдержка 5 мин при $700^{\circ} \mathrm{C}$ ) заметно, что процесс идет не равномерно по всей поверхности ленты, а более интенсивно в отдельно взятых областях, имеющих форму, близкую к сферической. На рис. 5а хорошо видны локализованные округлые очаги коррозии, размер которых составляет в среднем 0.3 мкм. Микроанализ регистрирует в этих областях большее содержание кислорода, чем в матрице (рис. 5b,c). В сплавах на медно-никелевой основе с добавками $\mathrm{Fe}$ и $\mathrm{Cr}$ в количестве менее 2 вес.\% не происходит выделения стабильных ОЦК-частиц, но существует, по-видимому, возможность образования локальных областей твердого раствора, обогащенных легирующим элементом. Именно в таких областях и образуются очаги коррозии. На этот факт указывает повышенное значение концентрации легирующего элемента в спектрах, снятых с очагов коррозии. Наличие в твердом растворе тройных сплавов с Fe и $\mathrm{Cr}$ сегрегаций или кластеров легирующего элемента не было обнаружено при электронно-микроскопическом исследовании. Для однозначного утверждения, что эти кластеры существуют необходимо использование методов прямого разрешения. Однако при локальном спектральном микроанализе поверхности исходных текстурованных лент значения содержания легирующего элемента в разных участках поверхности отличались, поэтому мы предполагаем, что сегрегации железа или хрома в исследуемых тройных сплавах могут присутствовать и инициировать появление первых очагов окисления.
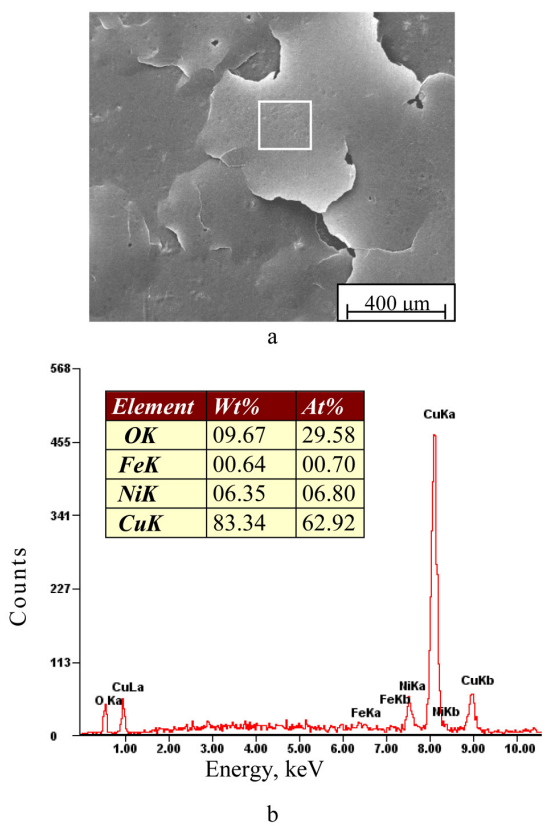

Рис. 4. Электронная микрофотография поверхности тройного сплава $\mathrm{Cu}-40 \% \mathrm{Ni}-1.4 \% \mathrm{Fe}$ после завершения термогравиметрических испытаний (а) и спектр с выделенного участка поверхности ленты (b).

Fig. 4. An electron micrograph of the surface of the ternary alloy $\mathrm{Cu}$ $40 \% \mathrm{Ni}-1.4 \% \mathrm{Fe}$ after completion of the test thermogravimetric (a) and a spectrum with a selected surface a section of tape (b).
В процессе увеличения времени окисления образование оксидов меди становится преобладающим и в спектрах, снятых с поверхности лент после завершения термогравиметрических испытаний (выдержка 250 мин при $700^{\circ} \mathrm{C}$ ) содержание меди и кислорода уже практически соответствует стехиометрическому составу закиси меди, содержание легирующего элемента снижается по сравнению с его средним содержанием в сплаве, а содержание никеля снижается более чем на порядок.

В тройном сплаве с ванадием процесс окисления идет с большей скоростью. В этом сплаве, в отличие от сплавов с железом и хромом, с самых ранних стадий окисления на поверхности лент не выявляются локализованные очаги коррозии. Уже после 5 мин выдержки при $700^{\circ} \mathrm{C}$ на поверхности ленты формируется сплошной оксидный слой, а содержание кислорода в снятых с окисленной поверхности спектрах достигает 5-6 вес.\%.
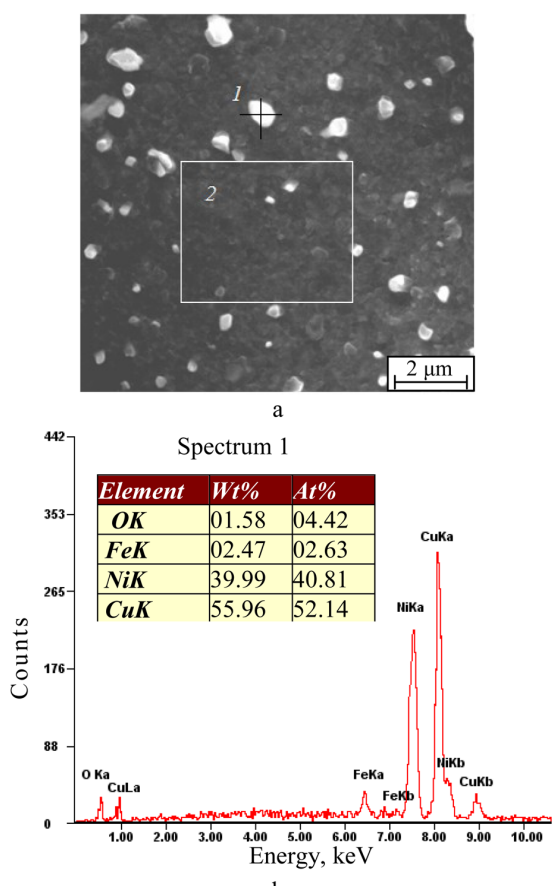

b

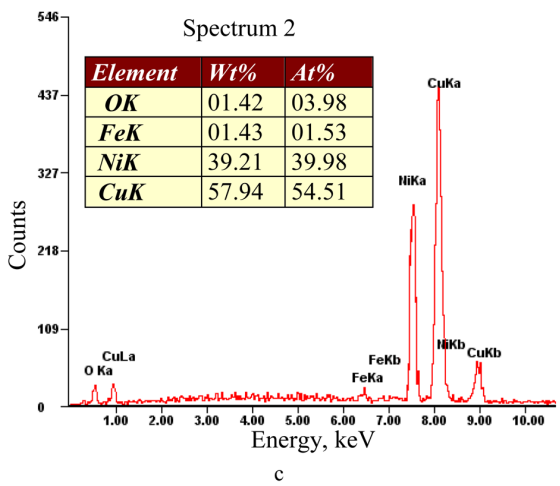

Рис. 5. Электронные микрофотографии поверхности тройного сплава $\mathrm{Cu}-40 \% \mathrm{Ni}-1.4 \% \mathrm{Fe}$ на ранних стадиях окисления (a) и спектры с очага коррозии (b) и выделенного участка поверхности ленты (c).

Fig. 5. Electron micrographs of the surface of the ternary alloy $\mathrm{Cu}$ $40 \% \mathrm{Ni}-1.4 \% \mathrm{Fe}$ in the early stages of oxidation (a) and corrosion hearth spectra (b) and the selected surface a section of tape (c). 


\section{6. Заключение}

В работе впервые проведен сравнительный анализ антикоррозионных свойств текстурованных тонких лент из двойных и тройных медных сплавов с малыми добавками (<2вес.\%) 3d-переходных металлов, таких как $\mathrm{Cr}$, $\mathrm{V}$ и $\mathrm{Fe}$.

Показано, что в лентах из сплавов $\mathrm{Cu}-0.4 \% \mathrm{Cr}$, $\mathrm{Cu}-1.6 \% \mathrm{Fe}$ и $\mathrm{Cu}-0.6 \% \mathrm{~V}$ окисление на начальных стадиях более интенсивно происходит на частицах легирующего элемента, о чем свидетельствует регистрация более высоких значений содержания кислорода в спектрах с этих частиц. Установлено, что размер выделяющихся в сплавах частиц в основном определяет относительную склонность сплава к окислению. Среди сплавов с выделениями дисперсных частиц наименьшей склонностью к окислению при температуре $700^{\circ} \mathrm{C}$, соответствующей характерным температурам нанесения буферных и сверхпроводящих слоев на металлическую подложку, обладает сплав $\mathrm{Cu}-0.4 \% \mathrm{Cr}$, в котором выделившиеся частицы имеют наименьший размер. Текстурованные ленты из этого сплава представляются наиболее перспективными из двойных сплавов для использования в качестве эпитаксиальных подложек.

Очевидно, что ленты из сплава $\mathrm{Cu}-0.6 \% \mathrm{~V}$ с антикоррозионными свойствами, уступающими даже лентам из чистой меди, не могут быть использованы для нанесения функциональных слоев при повышенных температурах.

$\mathrm{B}$ тройных сплавах с $\mathrm{Cr}$ и $\mathrm{Fe}$, не содержащих частиц c отличающимся от матрицы типом кристаллической решетки, процесс окисления начинается с образования локальных очагов коррозии. Активизация образования оксидов происходит, по-видимому, в тех областях, где наблюдается повышенная концентрация (кластеры) легирующего элемента.

Наиболее перспективными в качестве подложек для эпитаксиального нанесения буферных и сверхпроводящих слоев при повышенных температурах оказались текстурованные ленты из сплавов $\mathrm{Cu}-40 \% \mathrm{Ni}-1.2 \% \mathrm{Cr}$ и $\mathrm{Cu}-40 \% \mathrm{Ni}-1.4 \% \mathrm{Fe}$, обладающие помимо совершенной кубической текстуры и высоких прочностных свойств, наилучшими антикоррозионными свойствами.

Благодарность/Acknowledgements. Работа выполнена в рамках государственного задания ФАНО России по теме «Кристалл», № 01201463333 и частичной поддержке РФФИ № 16-03-00043.

\section{Литература/References}

1. B. Gallistl, R. Kirchschlager, A. W. Hassel. Phys. Stat. Solidi A. 209 (5), 875-879 (2012). Doi:10.1002/pssa.201100787.

2. C. V. Varanasi, P.N. Barnes, N. A. Yust. Supercond. Sci. Technol. 19, 85 - 95 (2006). Doi:10.1088/0953-2048/19 /1/015.

3. Yu. V. Khlebnikova, D.P. Rodionov, L. Yu. Egorova, T. R.Suaridze. The PhysicsofMetalsandMetallography. 117 (5), 500 - 507 (2016). DOI: 10.1134/S0031918X16050094.

4. Yu.V. Khlebnikova, I.V. Gervaseva, T.R. Suaridze, D. P. Rodionov, L. Yu. Egorova. Technical Physics Letters. 40 (10), 841 - 844 (2014). DOI: 10.1134/S1063785014100083.

5. Yu. V. Khlebnikova, D.P. Rodionov, I.V. Grevaseva, L. Yu. Egorova, T. R. Suaridze. Technical Physics. 60 (3), 389-399 (2015). DOI: 10.1134/S1063784215030111.

6. Yu.V. Khlebnikova, D.P. Rodionov, I.V. Gervas'eva, T.R. Suaridze, Yu.N. Akshentsev, V.A. Kazantsev. The Physics of Metals and Metallography. 115 (12), 1231 - 1240 (2014). Doi: 10.1134/S0031918X14120035.

7. H. Tian, H.L. Suo, O.V. Mishin, Y.B. Zhang, D. Juul Jensen, J.-C. Grivel. J Mater. Sci. 48, 4183 -4190 (2013). Doi: $10.1007 /$ s10853-013-7231-y.

8. A. Girard, C.E. Bruzek, J.L. Jorda, L. Ortega, J. L. Soubeyrouxet. J. Phys.: Conf. Ser. 43, 341 - 343 (2006).

9. C.V. Varanasi, L. Brunke, J. Burke, I. Maartense, N. Padmaja, H. Efstathiadis, Chaney A., P.N. Barnes. Supercond. Sci. Technol. 19, 896-901 (2006). Doi: 10.10 88/0953 - 2048/19/9/002.

10. J. L. Soubeyroux, C.E. Bruzek, A. Girard, J. L. Jorda. IEEE Trans. on applied superconductivity. 15 (2), 2687-2690 (2005). Doi: 10.1109/TASC.2005.847783.

11. Yu. V. Khlebnikova, D.P. Rodionov, I.V. Grevas'eva, T. R.Suaridze, V. A.Kazantsev. Technical Physics Letters. 41 (4), 341 - 343 (2015). DOI: 10.1134/S1063785015040094.

12. Y.V. Khlebnikova, I.V. Gervaseva, T.R. Suaridze, D. P. Rodionov, L. Y. Egorova. Letters on materials. 6 (3), 205-210 (2016).

13. J.D. Budai, D. K. Christen, A. Goyal, Q. He, D. M. Kroeger, D. F. Lee, F. A. List, D. P. Norton, M. Paranthaman, B. C. Sales, E. D. Specht. US Patent № 5,968,877. (1999).

14. D. P. Norton, C. Park, A. Goyal. US Patent №6,716,795. (2004).

15. O.E. Osintsev, V.N. Fedorov. Spravochnik. Copper and copper alloys. M., Mashinostroenie. (2004) P. 203 - 266. (in Russian) [O.Е. Осинцев, В.Н. Федоров. Справочник. Медь и медные сплавы: отечественные и зарубежные марки. М., Машиностроение. 2004. С. 203 - 266]. 